\title{
Expanding of Green and Renewable Energy as a Condition for Economy Transition to Sustainable Development
}

\author{
Gennady Kayachev ${ }^{1, *}$, Albina Chaplina ${ }^{1}$, Elena Gerasimova ${ }^{1}$, Radim Rybár ${ }^{2}$, and Elena \\ Usova $^{3}$ \\ ${ }^{1}$ Siberian Federal University, 660075 Lida Prushinskaya St. 2, Krasnoyarsk, Russia \\ ${ }^{2}$ Technical University Košice, Faculty BERG, Letná 9, 04001 Košice, Slovakia \\ ${ }^{3}$ T.F. Gorbachev Kuzbass State Technical University, Mezhdurechensk Branch, 652881 \\ Mezhdurechensk, 36 Stroiteley st., Russian Federation
}

\begin{abstract}
All over the world, the topic of green growth is relevant, that is, the growth of economies through the use of modern, environmentally sound, energy efficient technologies, including the use of alternative energy sources. In a modern, dynamically changing society, renewable energy sources are of interest to an increasing number of people. This interest is quite justified, since recently coherent problems of energy and environment are becoming more and more obvious. When discussing emerging problems, the leaders of states and international organizations more often come to the conclusion that in the future these problems can be solved only with the use of environmentally friendly renewable energy sources. The development of green and renewable energy is of particular importance for the Russian industry, in which, on the one hand, the fuel and energy sector occupies one of the main places. On the other hand, the transition to sustainable development is impossible without reducing the impact of energy on the environment, which is intended to contribute to the development of green and renewable energy.
\end{abstract}

\section{Introduction}

According to Art. 3 of the Federal Law of the Russian Federation "On Energy Saving and on Increasing Energy Efficiency ...", “... the following types of renewable energy sources include: solar energy, wind energy, energy of various waters, wave energy, thermal energy of the earth, air, water, biomass, plants and trees. In addition, this category includes production and consumption waste, except for waste that is obtained in the process of using hydrocarbon raw materials and fuel. These sources are also biogas, gas that is generated in coal mines" [1].

In modern world practice, renewable energy sources include: hydropower, solar energy, wind energy, geothermal energy, hydraulic energy, energy of sea currents, waves, tides, heat of the Earth, biomass. In a dynamically developing economy, the following

\footnotetext{
*Corresponding author: kayachev@mail.ru
} 
requirements are imposed on various energy sources:

- maneuverability (the ability to supply power in conditions of sharp jumps in power consumption);

- widespread availability;

- concentration of large capacities for the largest energy consumers;

- continuity of power supply (the ability to provide basic power consumption at any time);

- the possibility of forecasting and planning;

- characteristics of environmental and economic value.

\section{Materials and Methods}

China, the United States and Germany are the world leaders in installed renewable energy capacity. In terms of installed capacity, China ranks first in the world in small-scale energy. In the USA, such types of energy as wind, geothermal, and solar are more developed. Germany is characterized by the development of network photovoltaic energy. In the period from 2000 to 2008, the growth rate of electricity production in the world amounted to $3.4 \%$. Compared to this, the growth rate of solar energy was $32 \%$, wind energy $-27 \%$ [2].

In 2009, the total wind power capacity worldwide was $157.9 \mathrm{GW}$ (gigawatt). In 2007, wind farms produced approximately 200 billion $\mathrm{kWh}$, which is $1.3 \%$ of the world's electricity consumption as a percentage. The USA is the leader in terms of the installed capacity of wind power plants, and such countries as China, Spain and Germany are not lagging behind the leader [2].

In the last decade, the capacity of grid-connected photovoltaic installations in the world has grown by $69 \%$. In 2008, Germany became the leader in using the power of solar panels in power supply networks, followed by Japan, the USA, and China.

Regarding this type of raw material as biomass, it can be noted that it is used, as a rule, in solid form for industrial power generation. These are various types of wood fuel and waste that are used in the pulp and paper industry, municipal services, woodworking industry for the production of electricity and heat [3]. The production of refined fuel (pellets) is also becoming more widespread.

If we talk about the direct world experience of energy generation through the use of biomass, it can be noted that in 2008 the volume of energy generation using biomass amounted to 55.8 billion $\mathrm{kWh}$. In Europe, the supply of biomass-based fuels accounted for $3.7 \%$ of total energy consumption. In Finland, this figure reached 20\%, in Sweden $16 \%$. Biogas is also used in Europe. With the use of biogas, the generation of 17.3 billion $\mathrm{kWh}$ of electricity was ensured as of 2006. In recent years, the use of biomass has been increasing in Germany and China [4].

With regard to the use of geothermal sources, the following can be noted. Their economic use is widespread in countries such as France, Italy, USA, New Zealand, Iceland. For example, five geothermal power plants are successfully operating in Iceland. These power plants produce $26.5 \%$ of electricity and $90 \%$ of thermal energy in the country.

There is no single definition of the term "small hydroelectric power plant" for all countries. In order to characterize it, such a concept as installed capacity is used [5].

In the United States, small hydroelectric power plants include ones with a capacity not exceeding $30 \mathrm{MW}$. In Germany, Spain, Austria and other countries, small hydroelectric power plants are classified with a capacity of no more than $5 \mathrm{MW}$, in Ireland and Greece $10 \mathrm{MW}$. Currently, there are about 83 thousand small hydroelectric power plants in China [1].

In the EU countries, the share of renewable energy sources was $8.5 \%$ in 2005 , and there was a tendency for this indicator to grow. In Brussels, a directive "On the Promotion of the 
Use of Renewable Energy Sources" was developed and adopted. In accordance with this directive, by 2020 it is necessary to ensure:

- achieving an increase in the share of renewable energy sources in the total energy consumption up to $20 \%$;

- reducing the amount of greenhouse gas emissions by at least $20 \%$;

- the use of biofuels is mandatory for $10 \%$ of the total energy consumption.

In countries such as Austria, Latvia, Portugal, Sweden, Finland, the share of renewable energy sources was more than $20 \%$.

Russia lags behind the leading countries in the development and mastering of technologies for the use of renewable energy sources [6]. However, despite this circumstance, there are examples of the implementation of successful projects in this area. With further successful development, the projects of renewable energy sources can become significant and promising [7].

In Russia, the greatest demand is for peat and wood, which are varieties of biomass [8]. In 2005, the number of producers of briquettes and pellets increased significantly, this is due to the changes that have occurred this year. These changes have contributed to the development of the biofuels sector [9].

In addition to the increase in wood fuel consumption within the country, the export of this type of fuel is developing. The pellet market is currently focused on Western consumers. In addition, modern power plants for the use of biological gas began to appear in Russia. Thus, in Moscow, at the Kuryanovskiy wastewater treatment plant in 2009, a power plant was launched with a capacity of $10 \mathrm{MW}$.

Today in Russia there are not so many small hydroelectric power plants in comparison with other countries [10]. The existing hydroelectric power plants generate about 2.3 billion kWh of electricity annually. A New Energy Fund has been created in Russia for the construction of small hydroelectric power plants. The Foundation has developed a program for the development of small hydropower. Within the framework of this program, it is planned to create 275 small hydroelectric power plants in Russia by 2020, the total capacity of which is expected to be $1.86 \mathrm{GW}$ [1].

Wind power plants also operate on the territory of Russia. In 2005, the capacity of these plants was 13.3 MW, in 2008 - 16.5 MW, in 2013 - 17.5 MW. However, Russia still lags behind the European Union and China in terms of these indicators.

Regarding the implementation of projects in the field of solar energy, we can say the following about Russia: at this time, not so large in capacity, mainly local projects, are being implemented [11-12]. Solar batteries are used only at certain facilities, such as base stations in the Southern region of Vimpelcom OJSC (Beeline) and MTS OJSC.

\section{Results and Discussion}

The development of renewable energy sources is fueled by growing problems over time. Among these problems are the following:

1. The problem of meeting the growing energy needs of the growing population. Since 2001, global energy consumption has exceeded 500 EJ (exajoule) annually. According to various forecasts, by 2022 energy consumption in the world will increase by more than one and a half times. This growth in energy consumption will be driven by population growth in developing countries.

In modern conditions, there is a rapid depletion of fossil fuel reserves, for this reason it becomes less and less possible to meet growing energy needs with reasonable costs. Nuclear power can be considered as an option, but its development can be fully realized only with the transition to new types of reactors. In turn, the transition to new types of 
reactors requires the development and mastering of new technologies, which are costly. A certain alternative is the transition to thermonuclear energy, but this industry is at the stage of fundamental development. In such a situation, the expansion of the use of renewable energy sources is justified [4].

2. The problem of energy security. This problem is relevant, since there are a number of countries that depend on energy imports. Energy resources are distributed extremely unevenly throughout the world, which causes economic and political crises. Renewable energy sources may be available to varying degrees depending on the geographic location of the country [3].

3. The problem of environmental safety. It is worth paying attention to how modern energy influences the biosphere. The energy sector is responsible for $50 \%$ of all harmful emissions into the environment, including greenhouse gases. Renewable energy sources are more environmentally friendly [3].

In the south of Siberia, in the North Caucasus, in Primorye, solar collectors are used. For 2008-2010, in accordance with the decree of the Government of the Russian Federation of January 8, 2009 No. 1-r, it was planned to commission installations using renewable energy sources with a total capacity of more than one gigawatt and increase the generation from renewable energy sources by about $60 \%$ for implementation of target indicators for the volume and consumption of electrical energy.

The annual fuel consumption in Russia is 6 million tons; the number of diesel power plants is more than 5 thousand. The use of renewable energy sources is advisable in areas with centralized power supply.

In 2007, there were changes in legislation. Thus, Russian Public Company "United Energy Systems of Russia" voted for amendments to the already existing law "On the electric power industry" No. 35-FZ. On their initiative, articles were adopted to support the development of renewable energy. The adopted amendments not only for the first time give a definition of renewable energy sources in the legislation of the Russian Federation, but also define the tasks for the government to develop renewable energy sources.

The government has partially defined action plans to achieve these indicators. However, despite the partially built plans, the procedure for allocating subsidies to compensate for the cost of connecting to the power system has not yet been established, a mechanism for purchasing and pricing electricity, which is produced from renewable energy sources, has not been developed. The use of this type of energy should be aimed at compensating losses in power grids.

The greatest economic effect from renewable energy sources can be in the area of decentralized energy supply. However, for some reason this moment is missed in the Federal legislation of Russia.

Despite the targets set by the Government of the Russian Federation for renewable energy sources, the proposals of energy companies for the development of new capacities are at a low level. The growth rates of generation from the use of renewable energy sources remain rather low. On these problems, it is necessary to intensify the dialogue with energy companies, according to the association of environmental organizations.

The economic feasibility of designing and creating renewable energy sources, which include various installations, depends on the characteristics of the area. Local features play an important role in determining technical capabilities. For this reason, environmental organizations adhere to an individual approach to grid generating companies when planning the development of renewable energy sources.

The development of renewable energy sources in Russia is one of the most important factors in the modernization of the economy. The successful implementation of the modernization process is facilitated by the spread of innovative production facilities, the 
development of new technologies, and the development of small and medium-sized businesses. Subsequently, this will lead to an improvement in social conditions, the creation of new jobs, and an improvement in the environment.

The government should promote the new direction in the energy sector and create incentive mechanisms for small and medium-sized businesses in order to attract both financial and human resources to this industry. However, the government should participate in financing the development and implementation of renewable energy sources, since with the progress of this industry, the return on investment can become an additional source of profit for the state budget.

\section{Conclusion}

To achieve sustainable development, the main directions in the functioning of the world energy should be: increasing the efficiency of energy resources use, reducing the energy intensity of the world economy, ensuring energy security, as well as the formation of a new powerful independent renewable energy industry that can play a significant role in the greening of the fuel sector and increasing the share of clean energy in the world fuel and energy balance.

\section{References}

1. Federal Law "On Energy Saving and on Increasing Energy Efficiency and on Amending Certain Legislative Acts of the Russian Federation" of 23.11.2009 N 261FZ. URL: http://www.consultant.ru/document/cons_doc_LAW_93978/

2. M.S. Egorova, Bulletin of Science of Siberia, 3(9), 146-150 (2013)

3. E. Shavina, V. Prokofev, E3S Web Conf. 174, 02014 (2020)

4. T.A. Slepukhina, I.V. Andronova, Economy and Business, 12(125), 643-646 (2020)

5. A. P. Dzyuba, Economics and Innovation Management, 1, 51-62 (2021) DOI: 10.26730/2587-5574-2021-1-51-62

6. M. Cehlár, P. Rybár, J. Mihók, J. Engel, Journal of Mining and Geotechnical Engineering, 1, 4-23 (2019) doi: 10.26730/2618-7434-2019-1-04-23

7. A.N. Tokarev, Economics and Innovation Management, 3, 46-51 (2017) DOI: 10.26730/2587-5574-2017-3-46-51. DOI: 10.26730/2587-5574-2017-2-11-23

8. K. Čulková, H. Pavolová, S. Khouri, L.G. Shut'ko, Economics and Innovation Management, 3, 77-87 (2020) DOI: 10.26730/2587-5574-2020-3-77-87

9. A.G. Koryakov, M.V. Kulikov, Economics and Innovation Management, 4, 16-26 (2018) DOI: 10.26730/2587-5574-2018-4-16-26

10. O.E. Kalenov, S.N. Kukushkin, Economics and Innovation Management, 3, 88-96 (2020) DOI: 10.26730/2587-5574-2020-3-88-96

11. M. Beer, R. Rybár, M. Cehlár, S. Zhironkin, P. Sivák, Energies, 13(10), 2450 (2020)

12. P. Sivák, P. Tauš, R. Rybár, M. Beer, Z. Simkova, F. Banik, S., Zhironkin, J. Citbajová, Energies, 13(15), 3878 (2020) 